\title{
Temperature distribution analysis of monocrystalline photovoltaic panel for photovoltaic-thermoelectric generator (PV-TEG) hybrid application
}

\author{
Ruzaimi A. ${ }^{1}$, Shafie. S ${ }^{2}$, W.Z.W. Hassan ${ }^{3}$, N. Azis ${ }^{4}$, M. Effendy Ya'acob ${ }^{5}$, E. Elianddy ${ }^{6}$ \\ 1,2,3,4 Institute of Advanced Technology (ITMA), Universiti Putra Malaysia (UPM), Malaysia \\ ${ }^{2,3,4}$ Department of Electrical \& Electronic Engineering, Universiti Putra Malaysia (UPM), Malaysia \\ ${ }^{5}$ Department of Food \& Processing Engineering, Universiti Putra Malaysia (UPM), Malaysia \\ ${ }^{6}$ Department of Mechanical \& Manufacturing Engineering, Universiti Putra Malaysia (UPM), Malaysia
}

\section{Article Info}

\section{Article history:}

Received Jun 10, 2019

Revised Aug 12, 2019

Accepted Aug 28, 2019

\section{Keywords:}

Agrivoltaic

Greenhouse system

Photovoltaic (PV)

Solar

Thermoelectrc generator (TEG)

Thermoelectric (TE)

\begin{abstract}
An experiment has been carried out to prove the practicality of converting the waste heat from PV panels into electrical energy by observing the temperature levels and distribution of a conventional monocrystalline silicon (Mono c-Si) photovoltaic (PV) panels for photovoltaic-thermoelectric generator (PV-TEG) hybrid application of a Hybrid Agrivoltaic (HAV) Greenhouse System project. From the observation, highest temperature of the PV backside panel surface reached $81.1^{\circ} \mathrm{C}$ during solar noon and expected to reach even higher during hot season. The highest power output from the 160 numbers TEG modules in series and parallel configuration were calculated to reach 119 Watt during that time at $\Delta \mathrm{T} 56.1{ }^{\circ} \mathrm{C}$. This output is expected to fluctuate over the weather temperature fluctuation throughout the day. Meanwhile, for the heat distribution, it is best to apply the TEG arrays with optimized PV angle setup, where the temperature seems to be distributed evenly at all time, to provide optimum heat source to the TEG modules. It was concluded that the excess heat from the bottom surface of PV panels can be utilize by converting the heat via temperature differential to harvest additional electrical energy by integrating TEG system, hence maximizing the potential of solar radiation capacity in generating clean renewable energy.
\end{abstract}

Copyright $\odot 2020$ Institute of Advanced Engineering and Science. All rights reserved.

\section{Corresponding Author:}

Ruzaimi Ariffin,

Institute of Advanced Technology,

University Putra Malaysia (UPM), Malaysia.

Email: mohdruzaimi@gmail.com

\section{INTRODUCTION}

Development of renewable, green and environmental friendly energy is crucial for today's rising energy demand and depletion of natural resources issue. Solar energy in the form of light and heat is the largest potential clean energy resource that can be converted directly to electricity. Within past decade, combination of Photovoltaic (PV) with thermoelectric generator (TEG) technology is critically discussed and proven to be a good alternative utilizing solar waste heat in increasing power output efficiency compare to single PV system. TEG modules can directly convert excess thermal energy into electrical energy via Seeback effect through the temperature difference between back contact of the PV (which act as the heat input of the TEG) and cold junction of the TEG [1]. In addition, the use of TEG has many advantages as it's thermal structure has no moving parts, completely quiet, clean and can last for years, similar to photovoltaic module.

PV-TEG combined system has been applied in many configurations where both modules can either be physically integrated or separated. Common type of PV-TEG hybrid system developed were (1) by 
directly combining the TE modules at the back of PV panels/cell [2-4] and (2) by using spectrum splitter to separate and reflect the solar photon that cannot be absorb by PV to the TEG [5-10]. The system usually consists of PV modules or panels, TEG modules and a cooling system, where different elements were added or modified to maximize the output performance. The sum of power output from the PV and TEG modules results to the overall power output of the combined system [11]. Examples of such hybrid system can be found in vehicle exhaust [12] and telecommunication [13] system.

\section{PV/TEG HYBRID SYSTEM \& DEVELOPMENTS}

Figure 1 describe the electrical equivalent circuit of the hybrid system that combines PV and TEG module with separated power output. Solar radiation or sunlight, Q illuminate the PV cell generating electrical power, $P_{P V}$. The radiation that is not converted into electrical energy, conducts heat, $T_{P V}$ transferring it to TEG's hot side $T_{H . T E G}$, converting it to additional electrical power, $P_{T E G}$ and removed from the system through the cold side of the TEG, $T_{C . T E G}$ [14]. The total output electrical power of the hybrid system, $P_{P V . T E G}$, and efficiency, $\eta P_{V . T E G}$ is addressed by (1) and (2):

$$
\begin{aligned}
& P_{P V . T E G}=P_{P V}+P_{T E G} \\
& \eta_{P V . T E G}=\frac{P_{P V . T E G}}{Q}
\end{aligned}
$$

where $P_{P V}$ and $P_{T E G}$ are the electrical power of the PV and the TEG cells respectively, and $Q$ is the solar irradiance incident input energy equal to $Q=I_{S} A$ where $I_{S}$ is the solar intensity illuminating the top surface of a solar cell with an area, $A$.

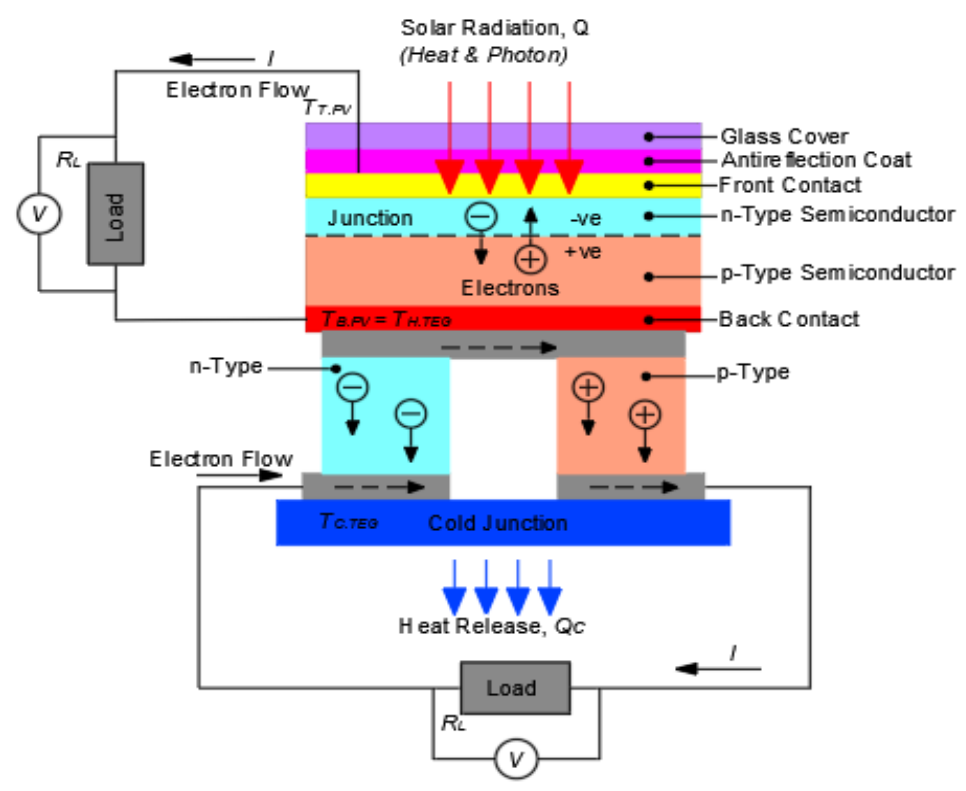

Figure 1. Equivalent circuit description of PV/TEG hybrid system

In earlier development, a model of roof mounted PV/TEG hybrid system has been developed by Van Sark [15] to measure the efficiency the system by mounting the TEG modules directly to the back of PV modules and focus was given to the combined electrical output. The efficiency of 11-14.7\% claimed in this system. Wang et al. [16] established a PV-TEG hybrid system composed of a series-connected dye-sensitized solar cell (DSSC), a solar selective absorber (SSA) and a TEG module which results from 9.39\% to $13.8 \%$ efficiency. Hsueh et al. [17] has reported that they have achieved the efficiency from $16.5 \%$ to $22.02 \%$ in their series-connected CuInGaSe2 (CIGS) PV cell with a TEG hybrid system. In another study, Lin et al. [18] studied the load matching in a PV-TEG hybrid system and the results proved that the solar irradiance, load resistances, and structure parameters of the TEG was corelated with the optimum performance of the hybrid system. In recent study, Wei Zhu et al. [19] fabricated a thermal concentrated PV-TEG hybrid system 
with optimized thermal management. They used copper plates serving as thermal concentrator and conductor which create large temperature difference between both side of TEG modules. This system has achieved the efficiency of $23 \%$ in outdoor test which was $25 \%$ more than that of PV cells.

Most of previous studies related to PV-TE hybrid system had assumed based on constant incident solar radiation whereas in fact, the solar radiation, and so with the temperature, varies all the time in the actual application.

\section{METHODOLOGY}

Previous study was considered where a conceptual design of PV/TEG Hybrid Greenhouse System were proposed [20]. This system took advantage of excess heat from a greenhouse PV roof panels by applying TEG system on its backside and using greenhouse internal temperature $\left(T_{I}\right)$ as TEG's cold side source $\left(T_{C . T E G}\right)$ for generating maximum power. First objective of this study is to verify that the top surface temperature $\left(T_{T . P V}\right)$ of a typical monocrystalline PV panel is equal (or almost equal) to its backside surface $\left(T_{B . P V}\right)$, which is later to be applied as the hot side temperature source for the TEG modules, $T_{H . T E G}$. Hence, $T_{H . T E G}=T_{B . P V}$. Then, thermal distribution of the bottom PV panel surface was characterized to identify the best potential positioning of the TEG modules to get the optimum power output for each module in the TEG system array.

\subsection{Experimental Setup 1: Average Daily Temperature for TEG Hot Side Application}

A replication of greenhouse system box was constructed to collect the daily average of top $\left(T_{T . P V}\right)$, bottom $\left(T_{B . P V}\right)$ (which is equivalent to $\left.T_{H . T E G}\right)$ and internal temperature $\left(T_{I}\right)$ to identify the heat excess of a typical mono-crystalline PV panel that can be converted to TEG power in normal condition. Data collected at an open area near the Institute of Advanced Technology, Universiti Putra Malaysia (300'70.57'N, 101'72'19.93'E). Figure 2 (a) and (b) shows the setup for the experiment purpose.

In this experiment, monocrystalline PV panel adopted was PV-YM0902, with the specification of size $670(\mathrm{~L})$ x $930(\mathrm{~W})$ x $30(\mathrm{H}) \mathrm{mm}$, Maximum Power $\left(\mathrm{P}_{\max . \mathrm{PV}}\right)=100 \mathrm{~W}$, Open Circuit Voltage $\left(\mathrm{V}_{\mathrm{OC} . \mathrm{PV}}\right)=21.5 \mathrm{~V}$, Short Circuit Current $\left(\mathrm{I}_{\mathrm{SC} . \mathrm{PV}}\right)=6.54 \mathrm{~A}$. The direction and elevation of the panel was determined by using Solar Noon Locator-UPM ${ }^{\odot}$ software to get the maximum PV power output (Figure 3) [21], while temperature data logger from EXTECH Instruments (SDL200 using K-Type thermocouple sensor) for surface contact temperature measurement. Daily solar radiation reading was also been taken using solar power meter logger (RSPRO ISM-410) for a specific day to analyze the relationship between solar irradiance level $\left(\mathrm{W} / \mathrm{m}^{2}\right)$ and temperature.

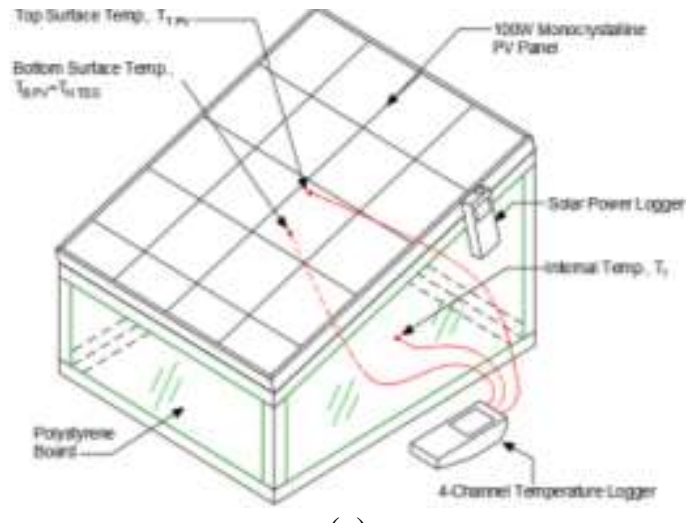

(a)

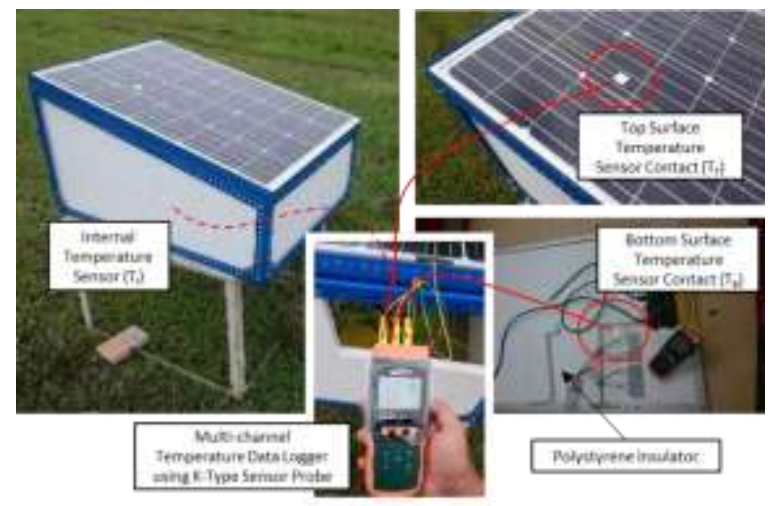

(b)

Figure 2. (a) Experimental setup 1 illustration, (b) Experimental setup 1: daily temperature reading for PV panel top $\left(T_{T . P V}\right)$, bottom $\left(T_{B . P V}\right)$ and internal temperature $\left(T_{I}\right)$ using K-Type surface contact thermocouple sensor temperature data logger

\subsection{Experimental Setup 2: Thermal Distribution}

The fact that the tilting angle and orientation of a PV panel strongly effect the PV power output has been proven many times in previous research [22-23]. PV panels must be tilted and oriented at optimum angles to absorb maximum solar energy available in a specific region. In this hybrid system, TEG modules 
are going to be mounted in series and parallel array combination at the backside of the PV panel. To analyze the thermal distribution characteristic of the optimized and flat angle PV setup to harvest maximum heat source from the PV panel bottom surface, two PV mounting structure was erected (Figure 4), one where the PV panel mounted in horizontal position $90^{\circ}$ facing sun (PV1) and the other one in $75^{\circ}$ facing sun (PV2), which is the fix average angle for optimized PV tilting angle in Malaysia throughout the year. Fluke thermal imager model Ti125 was used to obtain the thermal distribution of the surface, and due to limitation of the imager, PV panel was mounted 2 meter above the ground to capture thermal image of the whole PV panel module.



Figure 3. Solar Noon Locator-UPM ${ }^{\odot}$ to determine Optimimum PV panel Elevation and Azimuth setup [21]

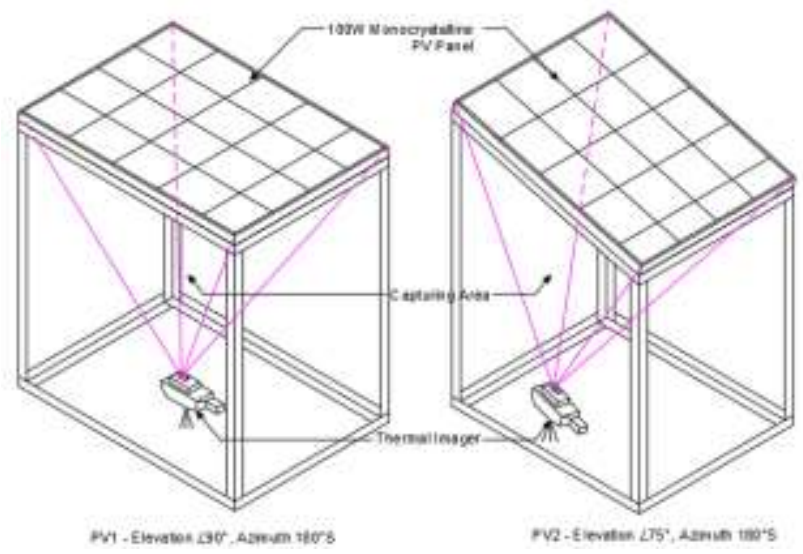

(a)

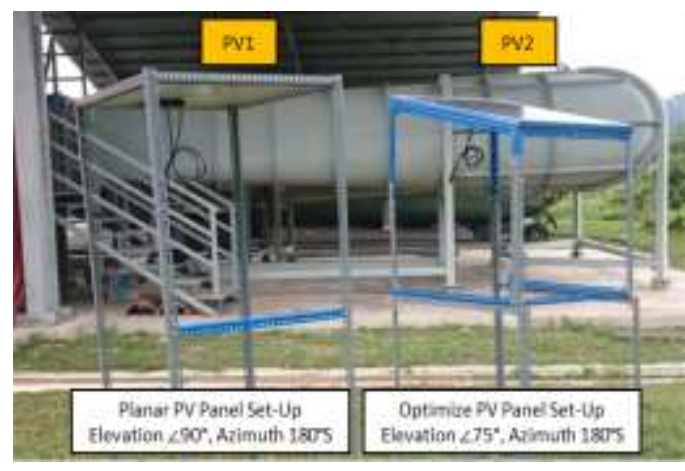

(b)

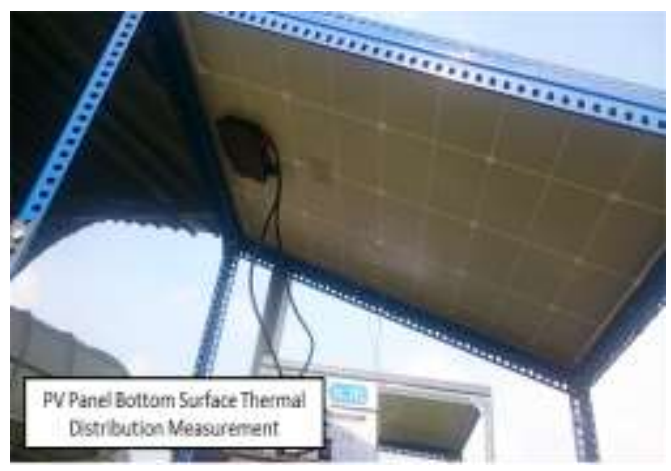

(c)

Figure 4. Experimental setup 2 - PV bottom surface thermal distribution analysis to identify the best TEG modules positioning to get the maximum heat source. (a) Experimental setup 2 illustration, (b) PV panel orientation setup, (c) Area of heat distribution captured 


\section{TEMPERATURE, SOLAR RADIATION AND HEAT DISTRIBUTION ANALYSIS}

In this section, a daily temperature reading and hourly thermal contour image of specific day were presented to prove the feasibility of applying the concept of combining PV and TEG into one hybrid system to fully utilize the solar energy.

\subsection{Average Daily Temperature for TEG Hot Side Application}

To present the implication of sunny and raining condition, Figure 5 shows hourly temperature reading sample that was specifically selected on 28 March 2018, 9.00AM until 6.00PM, logged at 1-hour interval. The PV panel bottom temperature increased abruptly from $44.1^{\circ} \mathrm{C}(9.00 \mathrm{AM})$ to highest temperature $81^{\circ} \mathrm{C}(12.00 \mathrm{PM})$ and maintained peak until after $1.00 \mathrm{PM}$ where the weather started to rain. The temperature decreases significantly from $2 \mathrm{PM}$ onwards between $35.1^{\circ} \mathrm{C}$ to $25.6^{\circ} \mathrm{C}$, to almost equivalent the internal air temperature. Result shows that bottom surface temperature is always almost equal to top surface temperature of the PV panel. The air temperature $\left(T_{I}\right)$ can be seen rising and dropping gradually underneath the PV panel, depending on fluctuation of temperature under the PV panel shadow. In the greenhouse system, the internal temperature will be set to $25^{\circ} \mathrm{C}$ which is the optimum photosynthesis temperature and maximum temperature growth for some cool season horticulture crops i.e broccoli, maize, cabbage and lettuce [24]. Hence, this temperature will be considered as the constant parameter absorbed at the TEG coldside $\left(T_{C . T E G}\right)$ later on.

The solar radiation $(Q)$ reading was also taken and the result shows that the fluctuation of temperature is proportional to the fluctuation of solar radiation. This result comes into agreement with Jin Zhang [5] and concludes that as the solar radiation varies and weather changes over time in actual operation, it reflects the temperature. It can be expected that the power output from the TEG array will fluctuate over the temperature fluctuation.

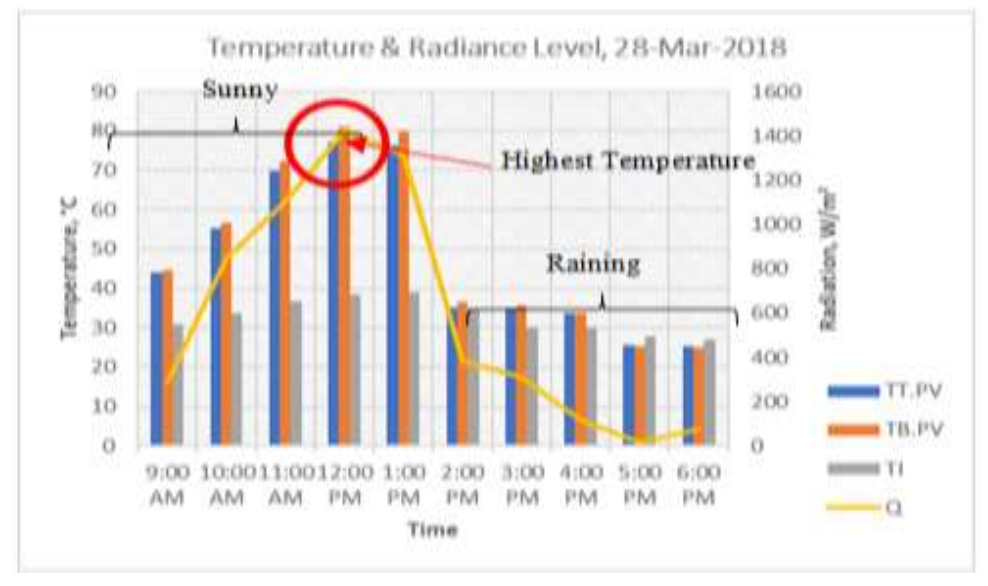

Figure 5. Temperature \& radiation level reading for Setup 1 on 28 March 2018

\subsection{Thermal Distribution}

Figure 6 shows the thermal image contour of bottom surface temperature distribution for horizontal (PV1) and optimized angle (PV2) PV panel setup. The thermal image was taken hourly on 14 March 2018 and presented in 2 hours' time interval from approximate 9:00AM, 11:00AM, 1:00PM, 3:00PM and 5:00PM. It can be seen at around 9:00AM, the heat distribution is evenly spread on PV2 while on PV1, the heat tends to be higher on it's right side, which is the sun rising angle. The average temperature for PV2 is slightly higher $\left(38.3^{\circ} \mathrm{C}\right)$ than PV1 $\left(35.8^{\circ} \mathrm{C}\right)$. While at 11:00AM, the heat distribution seems to be evenly spread on both PV1 and PV2 panel with the average temperature at almost the same value, $55.0^{\circ} \mathrm{C}$ and $55.6^{\circ} \mathrm{C}$ respectively. Same pattern observed at 1:00PM where the heat distribution for both PV panel was evenly distributed, and the temperature measured for both panel were $49.1^{\circ} \mathrm{C}$ and $49.0^{\circ} \mathrm{C}$ respectively. Even though the angle of PV2 was perpendicular to the sun, it shows that it has almost no significant effect to the temperature difference between PV1 and PV2. At around 3:00PM, the average temperature reading were $55.1^{\circ} \mathrm{C}$ and $53.8^{\circ} \mathrm{C}$ for PV1 and PV2 respectively. The thermal distribution contour is more even on PV2 even though the temperature were less $2^{\circ} \mathrm{C}$ from PV1. Finally, at 5:00PM, the average temperature reading for PV1 and PV2 were $42.0^{\circ} \mathrm{C}$ and $40.8^{\circ} \mathrm{C}$ respectively, where PV2 thermal distribution also seems to spread evenly than PV1. From the observation, the thermal distribution was best with optimized angle setup, 
where the temperature seems to be distributed evenly at all time, regardless the sun direction. In horizontal setup, the heat distribution pattern tends to be higher towards the direction of the sun.

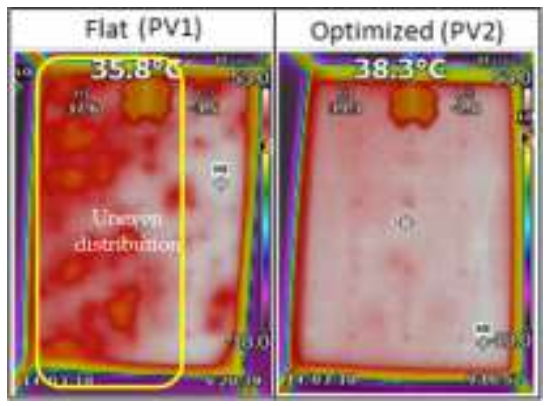

(a)

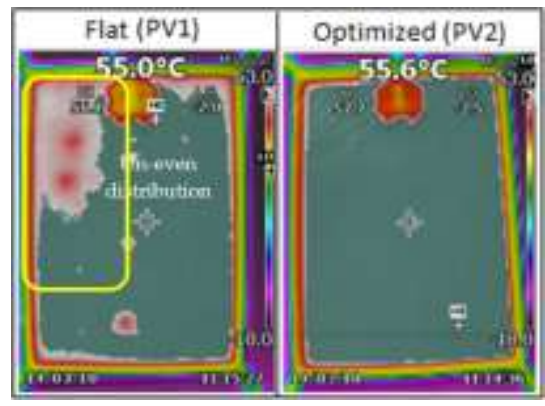

(b)

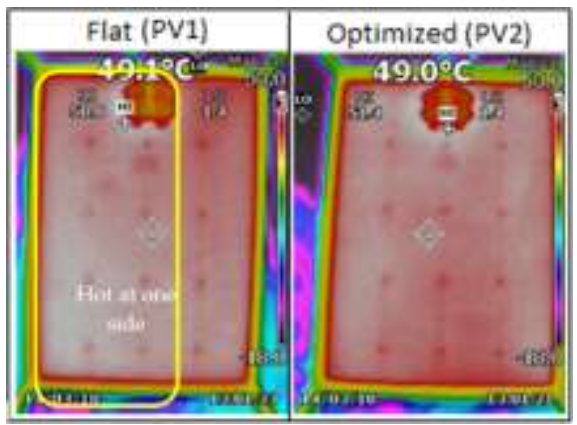

(c)

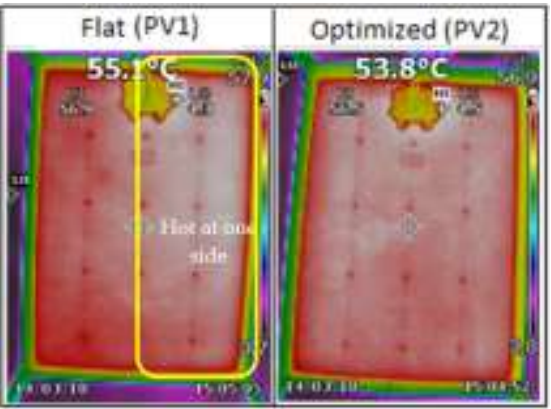

(d)

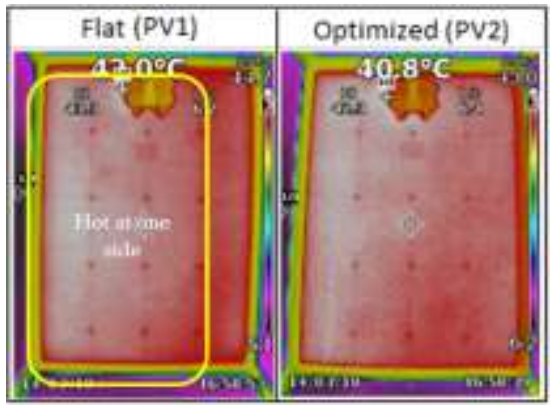

(e)

Figure 6. PV panel bottom surface thermal distribution image at approximate. (a) 9:00 AM, (b) 11:00 AM, (c) 1:00 PM, (d) 3:00 PM, (e) 5:00 PM, 14 March 2018

TEG modules can be connected in series to obtain higher output voltage, where voltage is added when current produced is the same. To obtain higher output current, TEG modules can be connected in parallel where current is added when voltage is the same. According to Kirchhoff's laws, theoretically, unbalance heat distribution will affect the whole TEG modules array power output due to different power characteristic (i.e voltage and current) generated from each module in the array due to unbalanced temperature difference [26]. Hence, for best application, it is advised to mount the TEG modules array from the middle to the right and left, upper and down side of optimized angle PV panel setup [27, 28].

\section{TEG POWER OUTPUT MATHEMATICAL MODELLING}

In Figure 7, we consider the backside area of the PV panel which each PV panel can be mounted up to 160 unit of TEG module given some gap between each other in series-parallel configuration. Common thermoelectric generators circuit contain several numbers of modules which is connected either in series, parallel, or in both arrangements. The typical circuit configuration is illustrated in Figure 8. It has a total number of modules $\left(N_{m}\right)$ with number of modules connected in series $\left(N_{s}\right)$ and in parallel $\left(N_{p}\right)$. The total number of modules in the system can be written as $N_{m}=N_{p} \times N_{s}$. 


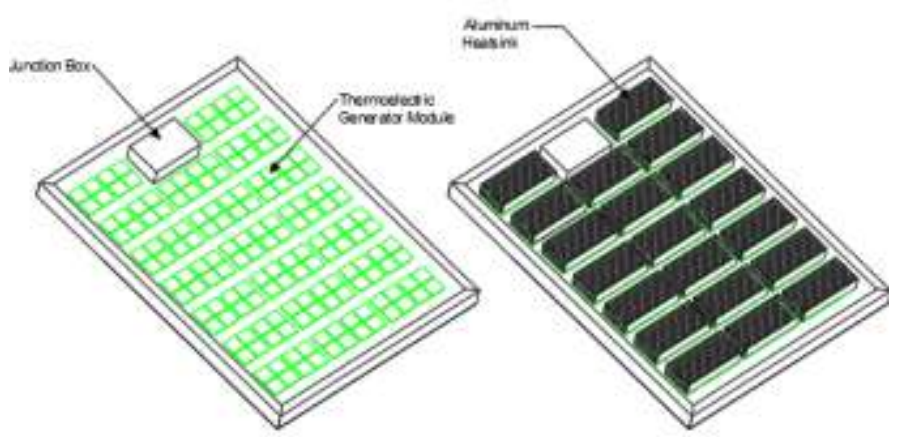

Figure 7. PV backside surface mounted with. a) Thermoelectric generators,

b) Thermoelectric generators and heatsinks.

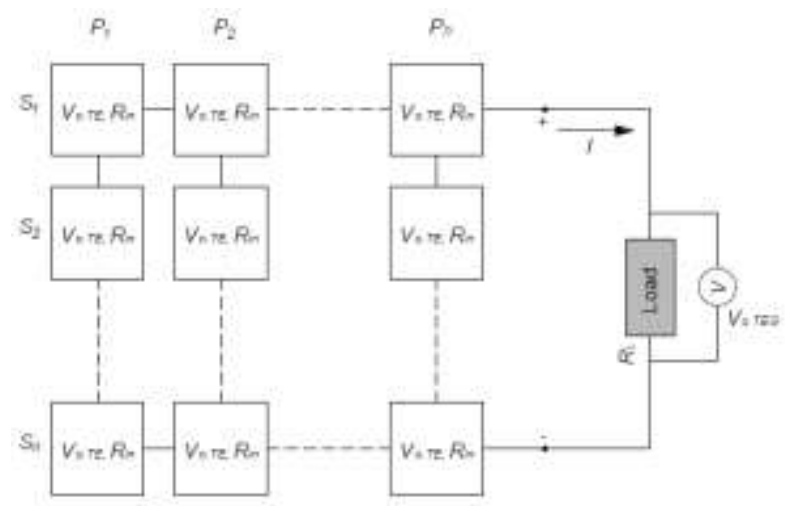

Figure 8. Typical thermoelectric generator with a Series-Parallel arrangement of modules

The current (I) passing through the load can be written as:

$$
I=\frac{N_{S} \times \alpha \times \Delta T}{\frac{N_{S} \times \alpha}{N_{p}}+R_{L}}
$$

where $\Delta \mathrm{T}$ is the temperature difference across the couple in $\mathrm{K}(T h-T c)$, and $R_{L}$ is the load resistance, and $\alpha$ is the average Seebeck coefficient (in volts $/{ }^{\circ} \mathrm{K}$ ) which can be expressed as:

$$
\alpha=\frac{V_{\max }}{T_{h}}
$$

The output voltage $\left(V_{O . T E G}\right)$ from the generator in volts is given by:

$$
V_{O . T E G}=\alpha \times \Delta T \times N_{s}
$$

The Output Power $\left(P_{O . T E G}\right)$ from the generator in watts is given by:

$$
P_{O . T E G}=V_{O . T E G} \times I=\frac{N_{m} \times(\alpha \times \Delta T)^{2}}{4 \times R_{\text {in }}}
$$

where $R_{\text {in }}$ is the module's average internal resistance.

The total heat input $\left(Q_{h}\right)$ to the generator in watts can be written as:

$$
Q_{h}=\left(S \times T_{h} \times I\right)-\left(0.5 \times I^{2} \times R_{\text {in }}\right)+\left(K_{C} \times \Delta T\right)
$$

where $K_{c}$ is the thermal conductance of the couple in watts $/{ }^{\circ} \mathrm{K}$.

Whereas, the efficiency $\left(\eta_{T E G}\right)$ of the generator is given by: 


$$
\eta_{T E G}=\frac{P_{O . T E G}}{Q_{h}} \times 100 \%
$$

In this low $\Delta \mathrm{T}$ application, it is important to choose the highest power output type of TEG modules at low temperature. Consider using TEG modules from Marlow Industries model TG12-8 [26], size 40 (L) x $40(\mathrm{~W}) \times 3.4(\mathrm{H}) \mathrm{mm}$, Cold Side Temperature, $T_{C}=27 \pm 2^{\circ} \mathrm{C}$, Internal Resistance $\left(R_{\text {in }}\right)=1.36 \sim 1.69$, figure of merit $(Z)=0.73$. Using the data from the temperature reading on 28 March 2018 and the TEG parameters, the expected power output from the TEG generator circuit can be calculated by applying (7) as shown in Table 1. It is noted that the highest power output is at 12:00 PM with power output generated 119 Watt where the $\Delta \mathrm{T}$ was $56.1^{\circ} \mathrm{C}$.

Table 1. Estimated TEG Circuit Power Output Table

\begin{tabular}{|c|c|c|c|c|c|}
\hline Date & Time & $\begin{array}{l}\text { PV Backside } \\
\text { Temp., } \mathrm{T}_{\text {B.PV }} \\
=\mathrm{T}_{\text {H.TEG }}\left({ }^{\circ} \mathrm{C}\right)\end{array}$ & $\begin{array}{c}\text { TEG Cold } \\
\text { Side, } \mathrm{T}_{\mathrm{C} . \mathrm{TEG}} \\
\left({ }^{\circ} \mathrm{C}\right)\end{array}$ & $\begin{array}{c}\text { Temp. } \\
\text { Difference, } \\
\Delta \mathrm{T}\left({ }^{\circ} \mathrm{C}\right)\end{array}$ & $\begin{array}{c}\text { TEG Power } \\
\text { Output } \\
\left(\mathrm{P}_{\text {O.TEG }}\right) \\
\end{array}$ \\
\hline \multirow{10}{*}{ 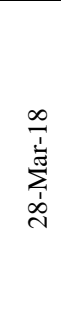 } & $9: 00$ & 44.7 & \multirow{10}{*}{25} & 19.7 & 14.70 \\
\hline & $10: 00$ & 56.8 & & 31.8 & 38.30 \\
\hline & $11: 00$ & 72.3 & & 47.3 & 84.73 \\
\hline & $12: 00$ & 81.1 & & 56.1 & 119.18 \\
\hline & $13: 00$ & 79.8 & & 54.8 & 113.72 \\
\hline & $14: 00$ & 36.5 & & 11.5 & 5.01 \\
\hline & $15: 00$ & 35.6 & & 10.6 & 4.26 \\
\hline & $16: 00$ & 33.6 & & 8.6 & 2.80 \\
\hline & $17: 00$ & 25.4 & & 0.4 & 0.01 \\
\hline & 18:00 & 25.1 & & 0.1 & 0.00 \\
\hline
\end{tabular}

\section{CONCLUSSION}

Two experiment has been carried out to prove the practicality of converting the waste heat from PV panels into electrical energy by observing the temperature levels and distribution of a common conventional monocrystalline silicon (Mono c-Si) photovoltaic (PV) panels for photovoltaic-thermoelectric generator (PV-TEG) hybrid application of a Hybrid Agrivoltaic (HAV) Greenhouse System project. Based on the results, the highest temperature of bottom PV panel surface panel reached $81.1^{\circ} \mathrm{C}$ during solar noon and expected to reach even higher during hot season. The highest power output from the 160 numbers TEG modules in series and parallel configuration were calculated to reach 119 Watt during that time at $\Delta \mathrm{T} 56.1$ ${ }^{\circ} \mathrm{C}$. This output is expected to fluctuate over the weather temperature fluctuation throughout the day. Meanwhile, for the heat distribution, it is best to apply the TEG arrays with optimized PV angle setup, where the temperature seems to be distributed evenly at all time, to provide optimum heat source to the TEG modules. It was concluded that the excess heat from the bottom surface of PV panels can be utilize by converting the heat via temperature differential to harvest additional electrical energy by integrating TEG system, hence maximizing the potential of solar radiation capacity in generating clean renewable energy. Further research can be considered on the hot side heat concentration or distribution, cold side temperature absorption, and the optimized TEG system power circuit design.

\section{ACKNOWLEDGEMENTS}

This works is currently supported by the Universiti Putra Malaysia grant number GPIPS/2018/9626800.

\section{REFERENCES}

[1] G Jeffrey Snyder, Eric S Toberer, "Complex Thermoelectric Materials," Nature Materials 7, pp. 105-114, 2008.

[2] A. Lekbira, S. Hassani, M.R.A. Ghania, C.K. Gana, S. Mekhilef, R. Saidur, "Improved energy conversion performance of a novel design of concentrated photovoltaic system combined with thermoelectric generator with advance cooling system," Energy Conversion and Management, vol. 177, pp. 19-29, 2018.

[3] Guiqiang Li, Xiao Chen, Yi Jin, "Analysis of the primary constraint conditions of an efficient photovoltaicthermoelectric hybrid system," Energies, vol. 10(1), 2017.

[4] Y.Jeyashree, P.B. Hepsiba, S.Indirani, A.Dominic Savio, Y.Sukhi, "Solar energy harvesting using hybrid photovoltaic and thermoelectric generating system," Global Journal of Pure and Applied Mathematics, vol. 19, pp. 5935-5944, 2017.

[5] Jin Zhang, Yimin Xuan, "Performance improvement of a photovoltaic - Thermoelectric hybrid system subjecting to fluctuant solar radiation", Renewable Energy, vol. 113, pp. 1551-1558, 2017. 
[6] E. Elsarrag, H. Pernau, J. Heuer, N. Roshan, Y. Alhorr, K. Bartholomé, "Spectrum splitting for efficient utilization of solar radiation: a novel photovoltaic-thermoelectric power generation system," Renew. Wind Water Sol., vol. 2, pp. 1-11, 2015.

[7] X. Ju, Z. Wang, G. Flamant, P. Li, W. Zhao, "Numerical analysis and optimization of a spectrum splitting concentration photovoltaic-thermoelectric hybrid system," Sol. Energy, vol. 86, pp. 1941-1954, 2012.

[8] P. Wahyu, Djafar Z., Syafaruddin, M. Mustofa, "The characterization of a spectrum splitter of TechSpec AOI $50.0 \mathrm{~mm}$ square hot and cold mirrors using a halogen light for a photovoltaic-thermoelectric generator hybrid," Energie, vol. 12(3), pp 1-13, 2019.

[9] M. Mustofa, P. Wahyu, Djafar Z, "A new hybrid of photovoltaic-thermoelectric generator with hot mirror as spectrum splitter," Journal of Physical Science 29(Supp. 2), pp. 63-75, 2018.

[10] E. Elsarrag, H. Pernau, J. Heuer, N. Roshan, Yousef A., K. Bartholomé, "Spectrum splitting for efficient utilization of solar radiation: a novel photovoltaic-thermoelectric power generation system," Renewables: Wind, Water, and Solar vol. 2(16), 2015.

[11] R.Bjørk, K.K.Nielsen, "The performance of a combined solar photovoltaic (PV) and thermoelectric generator (TEG) system," Solar Energy, vol. 120, pp. 187-194, 2015.

[12] Xiaodong Zhang, K. T. Chau, C. C. Chan, and Shuang Gao, "An automotive thermoelectric-photovoltaic hybrid energy system," Ener. Conv. \& Management, vol. 52(1), pp. 641-647, 2011.

[13] W. Roth, R. Kugele, A. Steinhuser, W. Schulz, and G. Hille, "Grid independent power supply for repeaters in mobile radio networks using photovoltaic/thermoelectric hybrid systems," 16th International Conference on Thermoelectrics, pp. 582-585, 1997.

[14] S. Singh, O. Isreal, Ibeagwu, R. Lamba, "Thermodynamic evaluation of irreversibility and optimum performance of a concentrated PV-TEG cogenerated hybrid system," Solar Energy, vol. 170, pp. 896-905, 2018.

[15] W.G.J.H.M. Van Sark, "Feasibility of photovoltaic - thermoelectric hybrid modules," Applied Energy; vol. 88(8), pp. 2785-2790, 2011.

[16] Wang N, Han L, He H, Park N.H, Koumoto K, "A novel high performance photovoltaic-thermoelectric hybrid device," Energy \& Environmental Science, (9), pp. 3676-3679, 2011.

[17] Hsueh T.J, Shieh J.M, Yeh Y.M, "Hybrid Cd-free CIGS solar cell/TEG device with ZnO nanowires," Prog. Photovolt: Res. Appl., pp. 507-512, 2015.

[18] Lin J, Liao T, Lin B, "Performance analysis and load matching of a photovoltaic thermoelectric hybrid system," Energy Conversion and Management, vol. 105, pp. 891-899, 2015.

[19] Wei Zhu, Yuan Deng, Yao Wang, Shengfei Shen Raza Gulfam,"High-performance photovoltaic-thermoelectric hybrid power generation system with optimized thermal management," Energy, vol. 100, pp. 91-101, 2016.

[20] M. Ruzaimi, Shafie S., W.Z.W. Hassan, N. Azis, M.Effendy Ya'acob "Conceptual design of hybrid photovoltaicthermoelectric generator (PV/TEG) for automated greenhouse system," IEEE 15th Student Conference on Research and Development (SCOReD), pp. 309-314, 2017.

[21] Shafie S., N. Azis, M.Z.A. Ab. Kadir, M.A.M. Radzi, W.H.W. Zuha, M.A Mustafa, "High efficiency portable solar generator utilizing optimum solar panel orientation," IEEE $5^{\text {th }}$ International Conference on Smart Instrumentation, Measurement and Application 2018 (ICSIMA), 2018.

[22] T. Khatib, A. Mohamed, M. Mahmoud, K. Sopian, "Optimization of the tilt angle of solar panels for Malaysia," Energy Sources, Part A: Recovery, Utilization, and Environmental Effects, vol. 37, pp. 606-613, 2015.

[23] M. Effendy Ya'acob, Hashim Hizam, Tamer T.N. Khatib, M.A.M. Radzi, "A comparative study of three types of grid connected photovoltaic systems based on actual performance," Energy Conversion and Management, vol. 78, pp. 8-13, 2014.

[24] Jerry L. Hatfield, John H. Prueger, "Temperature extremes: Effect on plant growth and development," Weather and Climate Extremes vol. 10, pp. 4-10, 2015.

[25] A.A Mansur, M. R. Amin, K.K. Islam, "Performance comparison of mismatch power loss minimization techniques in series-parallel PV array configurations," Energies, vol. 22(5), 2018.

[26] Custom Thermoelectric. Available online: https://www.marlow.com/products/power-generators (accessed on April 6, 2018).

[27] Ruzaimi A., Shafie. S, W.Z.W. Hassan, N. Azis, M. Effendy Ya'acob, Supeni E.E, "Photovoltaic panel temperature and heat distribution analysis for thermoelectric generator application," IEEE 5th International Conference on Smart Instrumentation, Measurement and Applications (ICSIMA), 2018.

[28] Verayiah, R., \& Iyadurai, A., "A comparison study on types of PV for grid connected photovoltaic power,"Indonesian Journal of Electrical Engineering and Computer Science, vol. 6, pp. 349-56, 2017.

\section{BIOGRAPHIES OF AUTHORS}

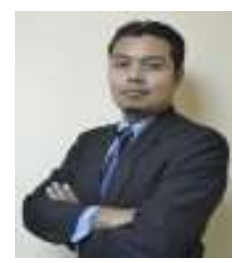

Mohd Ruzaimi currently persuing his $\mathrm{PhD}$ in Green Engineering at the Institute of Advanced Technology, Universiti Putra Malaysia. He is currently working on a Hybrid Agrivoltaic System project which focus on generating green energy by utilizing both light and thermal radiation from solar power source. 


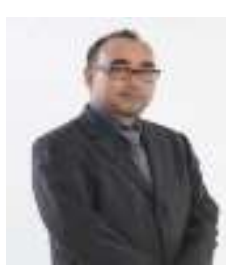

Suhaidi Shafie received the Bachelor of Engineering (Electrical and Electronics) from University of the Ryukyus, Japan in 2000. From 2000 to 2002, he was with ALPS Electric (M) Sdn. Bhd. He received the Master of Engineering (Electrical and Electronics) from Tokyo University of Agriculture and Technology, and the Doctor of Engineering (Nanovision) from Shizuoka University in 2005 and 2008, respectively. He is an Associate Professor in Universiti Putra Malaysia and the Head of Functional Devices Laboratory. Dr. Suhaidi is working in Mix Signal IC Design and Solar Energy research. His current projects include Ultra Low Power SAR ADC and High Efficiency Dye Sensitized Solar Cell. He is was the chapter chair of IEEE Circuits and Systems Malaysia Chapter and actively involves in IEEE CAS and IMS Malaysia Chapters activities.

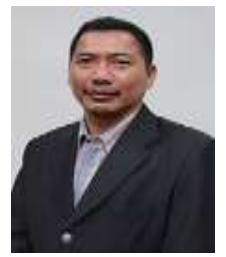

Wan Zuha Wan Hasan currently is an Associate Professor at the Department of Electrical and Electronic Engineering, Faculty of Engineering, Universiti Putra Malaysia. Received his PhD in Microelectronics in year 2010 from Universiti Kebangsaan Malaysia, while his MSc. Microelectronics (2001) from Universiti Putra Malaysia. Graduated as BSc. Electronic and Computer Engineering in year 1997 from Universiti Putra Malaysia. His research interest are in Microelectronics, Sensor Technology (Pressure Sensor for Medical and Robotic \& Automation Application), Robotic and Automation (Mobile Robot and, Automated Machine), Memory Testing includes Built-in Self-test and Self-diagnose.

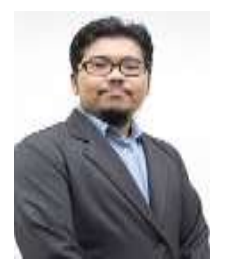

Norhafiz Azis received B. Eng degree in Electrical and Electronic Engineering (2007) from Universiti Putra Malaysia and PhD degree in Electrical Power Engineering (2012) from The University of Manchester in UK. Currently he is a Senior Lecturer at the Department of Electrical and Electronic Engineering, Universiti Putra Malaysia, Malaysia. His research interests are in-service ageing of transformer insulation, condition monitoring, asset management, high voltage engineering and alternative insulation materials for high voltage equipment.

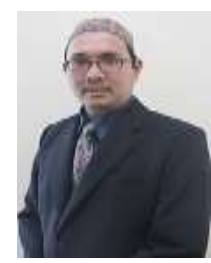

Mohammad Effendy Ya'acob graduated his engineering degree in multiple disciplinary, bachelor degree in Electrical and Electronic in 2003 and continued M. Sc in Engineering Management by the year 2005 both in Universiti Putra Malaysia. He successfully defended his $\mathrm{PhD}$ Doctorate in the field of Power Engineering. Effendy who's Electrical Engineer by profession have worked nearly 6 years in building maintenance, project engineering design and construction, and SHE concurrently. He was certified as Professional Electrical Engineer by the Board of Engineer Malaysia (BEM) in 2010 and become active member of The Institute of Engineers Malaysia (IEM). He was appointed as Senior Lecturer at the Department of Process and Food Engineering, Universiti Putra Malaysia since March 2015. He is currently the Exec. Committee for IEEE PES Malaysia and Hon. Treasurer for the Malaysian Society for Agricultural Engineering (MSAE). He also joined the Malaysian Society for Engineering and Society (MySET) as member. His research interests are in Green and Renewable Energy, AgriVoltaic System, Water Purification, Solar PV System, and Environmental Impact Assessment.

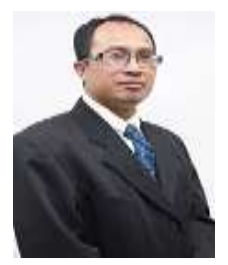

Dr. Eris Elianddy B Supeni is affiliated to Department of Mechanical and Manufacturing Engineering, University Putra Malaysia. Dr. Eris Elianddy B Supeni is currently providing services as Senior Lecturer. Dr. Eris Elianddy B Supeni has published numerous publications in various national and international peer-reviewed journals and presented scientific papers across the world. Because of the active association with different societies and academies as well as the contributions, Dr. Eris Elianddy B Supeni is been recognized by the subject experts around the world. Dr. Eris Elianddy B Supeni contributions are appreciated by various reputed awards. Dr. Eris Elianddy B Supeni clinical and scientific research interests include Renewable energy in wind turbine, Energy harvesting using smart material, FEA in Abaqus and CFD Ansys Fluent. 